\title{
PLACENTAL PASSAGE OF 17-HYDROXYCORTICOSTEROIDS: COMPARISON OF THE LEVELS IN MATERNAL AND FETAL PLASMA AND EFFECT OF ACTH AND HYDROCORTISONE ADMINISTRATION ${ }^{1}$
}

\author{
By CLAUDE J. MIGEON, HARRY PRYSTOWSKY, MELVIN M. GRUMBACH, ${ }^{2}$ AND \\ MARGARET C. BYRON \\ (From the Departments of Pediatrics and Obstetrics, The Johns Hopkins Hospital, \\ Baltimore, $M d$.)
}

(Submitted for publication December 5, 1955 ; accepted January 19, 1956)

A progressive rise in the levels of free plasma 17-hydroxycorticosteroids (17-OH-CS) during the course of pregnancy has been observed by a number of investigators (1-4). These findings are in conformity with the increase in urinary glucocorticoids previously reported (5). Normal adult concentrations have been found in the umbilical vein plasma obtained from the newborn infant at the time of delivery $(2,6-8)$, but significantly lower levels were observed in infants born by cesarean section ( 7 ).

The site of production and the nature of plasma $17-\mathrm{OH}-\mathrm{CS}$ found in increased amounts during pregnancy and at delivery has not yet been elucidated. The maternal and fetal adrenals, as well as the placenta could be the source of $C_{21}$ steroids with an $\alpha$-ketolic side chain. A rise in plasma and urinary corticosteroids has been reported in pregnant Addisonian patients $(9,10)$ which has suggested that during pregnancy an extra-adrenal source, namely the placenta, may be secreting such hormones. The prompt decrease in plasma 17$\mathrm{OH}-\mathrm{CS}$ in the newborn infant during the first few days of life (6), and the very low umbilical cord plasma concentrations in infants delivered by cesarean section (7) could be interpreted as indicating a lack of fetal production of corticosteroids. The rather constant ratio of $17-\mathrm{OH}-\mathrm{CS}$ in the maternal as compared to the umbilical cord plasma in cases of vaginal delivery has suggested that

1 This work was made possible by a Grant-in-Aid from the American Society of the Committee on Growth of the National Research Council, and by a research grant from the Division of Research Grants and Fellowships of the National Institutes of Health, United States Public Health Service.

2 Fellow of the National Foundation for Infantile Paralysis (1953-1955). Present Address: Babies Hospital, Columbia-Presbyterian Medical Center, New York, New York. fetal levels were only the reflection of maternal concentrations (8).

The present study was designed to clarify the role of placental transmission of free $17-\mathrm{OH}-\mathrm{CS}$ and to further identify the corticosteroids found in maternal and fetal circulations.

\section{METHODS}

The subjects in the present study were 33 pregnant females, 15 to 40 years of age. Vaginal delivery was performed in nine cases (Case Numbers 31 to 39). Cesarean section was deemed advisable in five cases because of placenta previa (Case Numbers 42 and 44) or uterine inertia (Case Numbers 40, 41, 43). Nineteen patients had an "elective, repeat cesarean" (Case Numbers 45 to 63 ), the section being performed approximately at term and before onset of labor. The majority of the vaginal deliveries were conducted under systemic analgesia and pudendal block anesthesia. Cesarean sections were usually accomplished with local infiltration of novocaine and intravenous Pentothal ${ }^{\circ}$ anesthesia. None of the subjects had toxemia or complications other than mechanical ones necessitating a cesarean section.

Blood samples were drawn in a heparinized syringe and the red cells were immediately separated from the plasma. The concentration of free 17-OH-CS was determined by the method of Nelson and Samuels (11).

(A) In the vaginal series, blood was collected during labor, 30 minutes to 4 hours prior to delivery. In the cesarean group (Case Numbers 40-51) specimens were obtained 30 minutes preceding anesthesia. A second sample was drawn simultaneously from the mothers and infants at the time of delivery. Finally, maternal blood was taken between 8 and 9 A.M., on the third and sometimes seventh postpartum day.

(B) An intravenous infusion of $25 \mathrm{mg}$. of ACTH (Armour ACTHAR, lot no. J21812) ${ }^{8}$ dissolved in 250 $\mathrm{ml}$. of 5 per cent dextrose in water, was administered over a period of six hours to seven patients scheduled for an "elective, repeat cesarean section" (Case Number 52 to 58 ). The infusion was started at 8 A.M., after a

8 The ACTH preparation used in this study was generously provided by Armour Laboratories, Chicago, IIlinois. 
TABLE I

Levels of 17-OH-CS in maternal and cord plasma in cases of vaginal delivery and cesarean section

\begin{tabular}{|c|c|c|c|c|c|c|c|c|c|}
\hline \multirow{4}{*}{ Dolivery } & \multirow{4}{*}{$\begin{array}{c}\text { Gace } \\
\text { Minberer }\end{array}$} & \multirow{4}{*}{$\begin{array}{l}\text { Age } \\
\text { (5re.) }\end{array}$} & \multirow{4}{*}{ Race } & \multirow{4}{*}{$\begin{array}{l}\text { Duration } \\
\text { of } \\
\text { Prognancy } \\
\text { (Hoolos) }\end{array}$} & \multirow{2}{*}{\multicolumn{2}{|c|}{ 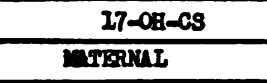 }} & \multicolumn{3}{|c|}{ (18, por $200 \mathrm{ml}$, pleasa) } \\
\hline & & & & & & & \multirow{3}{*}{ con } & \multirow{2}{*}{\multicolumn{2}{|c|}{$\begin{array}{c}\text { MATKRIULL } \\
\text { Poot Dolivery }\end{array}$}} \\
\hline & & & & & Pre & At & & & \\
\hline & & & & & Dalivery & Delivery & & $\begin{array}{l}\text { 3rd } \\
\text { Dero }\end{array}$ & $\begin{array}{l}\text { 7th } \\
\text { Des }\end{array}$ \\
\hline Vaginal & 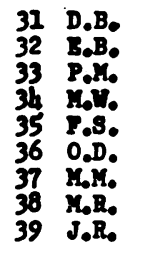 & $\begin{array}{l}37 \\
36 \\
15 \\
22 \\
32 \\
35 \\
27 \\
28 \\
22\end{array}$ & $\begin{array}{l}c \\
c \\
c \\
C \\
c \\
c \\
C \\
W \\
W\end{array}$ & $\begin{array}{l}39 \\
37 \\
36 \\
39 \\
41 \\
41 \\
32 \\
37 \\
39\end{array}$ & $\begin{array}{l}26.4 \\
24.0 \\
53.0 \\
47.5 \\
49.5 \\
41.8 \\
52.5 \\
72.0 \\
69.0\end{array}$ & $\begin{array}{l}38.5 \\
41.5 \\
46.0 \\
52.0 \\
54.4 \\
56.0 \\
67.0 \\
76.1 \\
78.0\end{array}$ & $\begin{array}{l}10.9 \\
18.6 \\
0.2 \\
27.0 \\
12.0 \\
16.5 \\
13.5 \\
65.8 \\
14.3\end{array}$ & $\begin{array}{l}25.2 \\
14.9 \\
21.5 \\
43.0 \\
5.9 \\
16.5 \\
40.0 \\
30.5 \\
29.4\end{array}$ & \\
\hline $\begin{array}{l}\text { Indicated } \\
\text { Cesarean }\end{array}$ & $\begin{array}{ll}40 & S_{0} H_{0} \\
41 & S_{0} H_{0} \\
42 & M_{0} Y_{0} \\
43 & M_{0} P_{0} \\
\text { Wh } & I_{0} G_{0}\end{array}$ & $\begin{array}{l}32 \\
29 \\
22 \\
32 \\
30\end{array}$ & $\begin{array}{l}w \\
c \\
w \\
w \\
w\end{array}$ & $\begin{array}{l}42 \\
40 \\
35 \\
43 \\
44\end{array}$ & $\begin{array}{l}23.0 \\
19.0 \\
31.0 \\
48.0\end{array}$ & $\begin{array}{l}28.0 \\
34.0 \\
47.0 \\
66.0 \\
98.5\end{array}$ & $\begin{array}{r}5.0 \\
7.0 \\
22.0 \\
16.5 \\
13.6\end{array}$ & $\begin{array}{l}\overline{34.0} \\
53.2 \\
68.4 \\
18.0\end{array}$ & $\begin{array}{l}29.2 \\
15.8 \\
29.7 \\
14.0 \\
16.5\end{array}$ \\
\hline $\begin{array}{l}\text { Beotive } \\
\text { Bopeat } \\
\text { Cesarean }\end{array}$ & 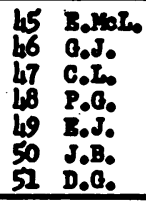 & $\begin{array}{l}27 \\
25 \\
34 \\
26 \\
20 \\
26 \\
20 \\
\end{array}$ & $\begin{array}{l}c \\
w \\
w \\
w \\
c \\
w \\
c\end{array}$ & $\begin{array}{l}19 \\
38 \\
38 \\
39 \\
38 \\
39 \\
38 \\
\end{array}$ & $\begin{array}{l}6.8 \\
14.0 \\
23.6 \\
17.0 \\
10.2 \\
18.4 \\
24.04\end{array}$ & $\begin{array}{r}8.6 \\
20.6 \\
22.5 \\
23.0 \\
32.4 \\
33.5 \\
35.8\end{array}$ & $\begin{array}{l}0.6 \\
4.3 \\
1.04 \\
5.0 \\
9.5 \\
8.6 \\
0.3\end{array}$ & $\begin{array}{l}25.0 \\
25.5 \\
16.0 \\
-18.4 \\
-\end{array}$ & $\begin{array}{l}20.3 \\
10.5 \\
23.2 \\
- \\
20.4 \\
-\end{array}$ \\
\hline
\end{tabular}

control blood sample had been drawn, and terminated at the time of delivery, which took place at 2 P.M. Additional blood specimens were collected from the mother, two and four hours after the start of the infusion and simultaneously from the mother and the cord at delivery.

(C) An intravenous infusion of hydrocortisone (Upjohn, Cortef 0.5 per cent $\mathrm{w} / \mathrm{v}$ ) dissolved in $250 \mathrm{ml}$. of 5 per cent dextrose in water was started at 8 A.M. and given over a period of 30 minutes to a second group of 5 patients (Case Numbers 59 to 63) scheduled for "elective, repeat cesarean section." The surgical procedure was begun just after the start of the infusion and delivery was performed at the termination of steroid administration. A control blood sample was obtained from the mother immediately prior to this procedure; maternal and cord specimens were collected simultaneously at delivery. Patients 59 to 61 received $50 \mathrm{mg}$. of hydrocortisone and patients 62 and $63,100 \mathrm{mg}$.

(D) To characterize further the free plasma $17-\mathrm{OH}-\mathrm{CS}$ present in the maternal and fetal circulation at the time of delivery, blood samples were collected, pooled and extracted with chloroform. After evaporation the residue was chromatographed on Florisil columns and the 25 per cent methanol in chloroform eluate was evaporated. The residue was applied to Whatman No. 2 paper and chromatographed in the methanol: water $(55: 45)$ /benzene system of Bush (12). The chromatograms were studied as previously described (13).

- The I.V. preparation of Hydrocortisone was kindly supplied by the Upjohn Co., Kalamazoo, Michigan.

\section{RESULTS}

(A) Table I shows the levels of free 17-OH-CS in maternal plasma before and at delivery, and in the immediate postpartum period in pregnancies terminated by vaginal delivery, indicated cesarean section, and "elective, repeat cesarean section." These values are compared to the levels found in the umbilical vein plasma at birth. Labor generally caused a rise in the maternal concentrations as evidenced by the higher predelivery values in the vaginal series when compared to those obtained in the elective cesarean group. The trauma of parturition also appeared to increase the levels of the mother. Irrespective of the method of delivery, the $17-\mathrm{OH}-\mathrm{CS}$ concentration in the cord plasma was invariably less than that found in the mother (see Figures 1 and 2). Furthermore, the levels in the umbilical vein plasma of infants born by elective cesarean section were lower than those obtained in the other two groups of infants.

(B) The response of maternal 17-OH-CS levels to ACTH administration in cases of "elective repeat cesarean section" (see Table II) was similar to that observed in nonpregnant females (14). This is in contrast to the hyperresponsiveness reported by Christy, Wallace, and Jailer (15) 


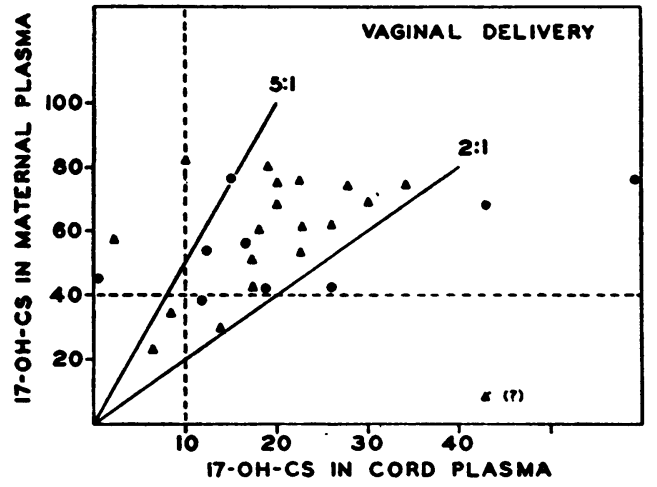

Fig. 1. Relationship between 17-OH-CS Levels in Maternal and Cord Plasma in Cases of Vaginal Delivery

The black circles are the values reported in the present paper; the black triangles are the values reported in a previous paper (8).

The horizontal broken line indicates the $40 \mu \mathrm{g}$. level for maternal plasma; most values are over this line. The vertical broken line indicates the $10 \mu \mathrm{g}$. level for cord plasma; most cord values are higher than $10 \mu \mathrm{g}$.

The full lines are indicative of a ratio maternal:cord value of $2: 1$ and $5: 1$. It can be seen that most values are situated between the two lines, demonstrating the existence of a concentration gradient between the maternal and cord 17-OH-CS.

in the third trimester of pregnancy; however, the method employed by these authors was less specific than the technique used in the present study and the former may be determining some steroids that the latter method does not. In blood specimens obtained simultaneously from the mother and the newborn infant at delivery, the concentration of $17-\mathrm{OH}-\mathrm{CS}$ in the cord plasma was one-third

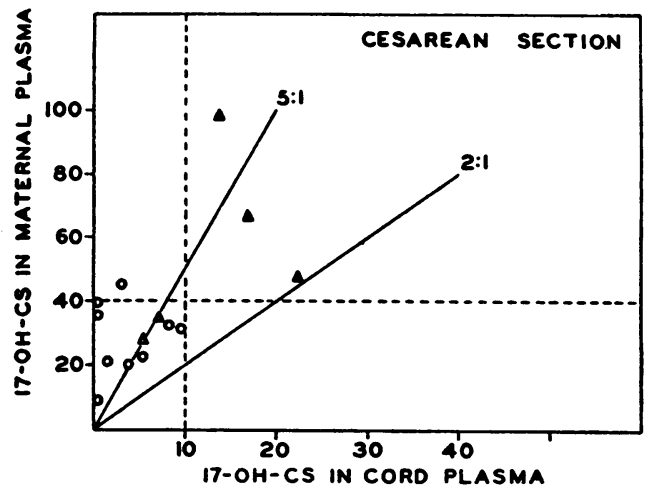

Fig. 2. Relationship between 17-OH-CS LeVEls IN Maternal and Cord Plasma in Cases of Cesarean Section

The open triangles are the cases of "indicated cesarean"; the open circles, the "elective cesareans." The values of two cases reported in a previous paper (8) were added on the figure. It can be noted that in all the elective cesareans, the maternal values were lower than $40 \mu \mathrm{g}$. and those in cord blood lower than $10 \mu \mathrm{g}$.

to one-half that found in the maternal plasma. These cord levels were without exception higher than those observed in the group delivered by "elective, repeat cesarean section," not stimulated with ACTH.

(C) The increase of the 17-OH-CS levels obtained in maternal and cord plasma was directly proportional to the amount of compound $F$ administered (Table III). Although strikingly elevated, the levels in the cord plasma were invariably lower than the maternal values. The passage of hydrocortisone infused to the mother across the placenta to the fetus is demonstrated by comparing

TABLE II

Effect of ACTH administration on 17-OH-CS levels in maternal and cord plasma in cases of elective, repeat cesarean section

\begin{tabular}{|c|c|c|c|c|c|c|c|c|c|c|c|}
\hline \multirow{3}{*}{\multicolumn{2}{|c|}{$\begin{array}{l}\text { Cacs } \\
\text { Nuberes }\end{array}$}} & \multirow{3}{*}{$\begin{array}{c}1 \notin 0 \\
(\text { Ire.) }\end{array}$} & \multirow{3}{*}{ Reos } & \multirow{3}{*}{$\begin{array}{l}\text { Duratice } \\
\text { of } \\
\text { Prognency } \\
\text { (Iivelce) }\end{array}$} & \multirow{3}{*}{\multicolumn{2}{|c|}{ rodication }} & \multicolumn{2}{|c|}{$27-c t-c s$} & \multicolumn{3}{|c|}{ (6) por 100 =1. plasea) } \\
\hline & & & & & & & \multicolumn{4}{|c|}{ Mr.xII } & \multirow[b]{2}{*}{$\begin{array}{l}\cos 0 \\
2 \text { P.X }\end{array}$} \\
\hline & & & & & & & $\begin{array}{l}8 \text { A.M. }_{0} \\
\text { (Cootrol) }\end{array}$ & $101.5 \times 16$ & 12 Yocen & $\begin{array}{c}2 \text { P.I. } \\
\text { (Dolif- } \\
\text { ory) }\end{array}$ & \\
\hline & I.D. & 27 & $\boldsymbol{u}$ & 38 & \multicolumn{2}{|c|}{25 unte $10 \mathrm{Cr}$} & 30.4 & 50.5 & 71.5 & 61.0 & 30.5 \\
\hline 53 & B.C. & 100 & C & 37 & & - & 12.3 & 23.0 & 22.0 & 32.6 & 21.5 \\
\hline & A.t. & 39 & c & 39 & 25 & - & 25.7 & 30.8 & 36.0 & 34.0 & 25.0 \\
\hline 55 & B.x. & 26 & C & 37 & & $\bullet$ & 5.5 & 28.0 & 33.0 & 38.6 & 23.5 \\
\hline & R.c. & 37 & c & 42 & 25 & - & 24.7 & 23.0 & 20.0 & 36.2 & 23.7 \\
\hline & C.D. & 31 & c & 38 & 25 & - & 24.1 & 34.2 & 49.3 & 54.5 & 23.0 \\
\hline & Row. & $2 h$ & c & 38 & 25 & $\bullet$ & 22.5 & 41.0 & 44.7 & 48.2 & 22.7 \\
\hline
\end{tabular}


TABLE II

Effect of compound $F$ administration on 17-OH-CS levels in maternal and cord plasma cases of elective, repeat cesarean section

\begin{tabular}{|c|c|c|c|c|c|c|c|c|}
\hline \multirow{3}{*}{\multicolumn{2}{|c|}{$\begin{array}{l}\text { Case } \\
\text { Number }\end{array}$}} & \multirow{3}{*}{$\begin{array}{c}180 \\
\text { (Ire.) }\end{array}$} & \multirow{3}{*}{ Rece } & \multirow{3}{*}{$\begin{array}{l}\text { Duration } \\
\text { of } \\
\text { Prognancy } \\
\text { (Woeles) }\end{array}$} & \multirow{3}{*}{ Modication } & \multicolumn{3}{|c|}{ 17-CH-CS pg. par $100 \mathrm{ml}$. } \\
\hline & & & & & & \multicolumn{2}{|c|}{ Sutarnel } & \multirow{2}{*}{ Card } \\
\hline & & & & & & Contrial & Os Cpd. F & \\
\hline 59 & M.S. & 39 & $\mathbf{w}$ & 39 & $50 \mathrm{mg.IV} \mathrm{epdor}$ & 21.1 & 278.0 & 50 dh \\
\hline 60 & Y.P. & 31 & v & 38 & 50 m.IV epd.F & 29.2 & 258.0 & 67.0 \\
\hline 61 & A.l. & 20 & $\boldsymbol{\psi}$ & 39 & $50 \mathrm{mg.IV} \mathrm{cpd} . \mathrm{F}$ & 17.6 & $\nu_{4} 8.0$ & 77.0 \\
\hline & s.c. & 23 & C & 39 & 100 ng.IV cpd.F & 25.4 & 302.0 & 86.5 \\
\hline & A.J. & 36 & C & 38 & 100 ag.IV cpdor & 24.0 & 326.0 & 1050 \\
\hline
\end{tabular}

the $17-\mathrm{OH}-\mathrm{CS}$ levels in cord plasma in the control group of "elective repeat cesarean sections" and those in the group who received compound F.

(D) The method of Nelson and Samuels (11) was shown to measure mainly free plasma hydrocortisone. There exists a satisfactory correlation between results obtained by this method and paper chromatographic techniques in normal individuals and following ACTH administration (16), as well as in patients undergoing surgical or medical stress, and in moribund individuals (13). It was found in the present study that the values obtained for 17-OH-CS by the method of Nelson and Samuels were in good agreement with the amount of compound $\mathrm{F}$ eluted from the paper chromatogram of the corresponding extract (Table IV). A spot with the mobility of compound B could not be observed on the paper chromatograms of either maternal or fetal extracts. This possibly may be attributed to our use of methods not sufficiently sensitive to detect quantities of compound B less than 5 to 8 micrograms.

\section{DISCUSSION}

The role which adrenal secretion, tissue factors, alterations in the rate of hepatic degradation and conjugation, and kidney clearance, respectively, may play in contributing to the elevated levels of free plasma 17-OH-CS during pregnancy, labor and delivery is not known. That increased plasma concentrations do not necessarily reflect an increase in hormone production, is evidenced by the studies of corticosteroid metabolism in dying patients (17), and in patients subjected to surgical procedures $(18,19)$. In many instances, the maternal levels of $17-\mathrm{OH}-\mathrm{CS}$ in cases of vaginal delivery were found to be higher than those observed after administration of a maximal dose of ACTH to normal, nonpregnant females; this raises the

TABLE IV

Comparison of the results obtained by the method of Nelson and Samuels and paper chromatographic techniques

\begin{tabular}{|c|c|c|c|}
\hline 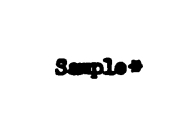 & Dellivery & 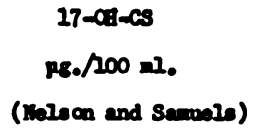 & $\begin{array}{c}\text { Compound I } \\
p 8 . / 100 \text { al. } \\
\text { (paper chronatogeraphy) }\end{array}$ \\
\hline Maternel placen & Vaginal dolivery & 56.0 & 47.6 \\
\hline Cord planm & Fapdnel dalivery & 21.0 & Th.5 \\
\hline Meternal placese & Coserrean escticn & 23.5 & 18.0 \\
\hline
\end{tabular}

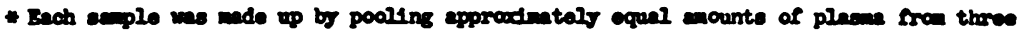


possibility that extra adrenal factors might be involved, although it has been suggested that there is a hyperresponsiveness of the adrenal cortex to exogenous ACTH administration during the third trimester of pregnancy (15).

The infusion of compound $\mathrm{F}$ to the mother produced an increase in her 17-OH-CS levels as normally expected, but the fact that cord values were higher than those obtained when no steroid was administered strongly suggests that the placenta is permeable to compound $F$. It is the first definite demonstration that a steroid can go through the "placental barrier."

This process, however, does not appear to be a simple diffusion. A rather constant relationship was found to exist between the levels of plasma 17-OH-CS in the mother and fetus at birth. In most instances, irrespective of the method of delivery and whether ACTH or compound $\mathrm{F}$ was administered to the mother before delivery, the values in cord plasma were 20 to 50 per cent of those in the mother. It seems highly improbable that the lower levels in the infant may have been due to a slow equilibration between maternal and fetal circulations, or to a rapid destruction of 17 $\mathrm{OH}-\mathrm{CS}$ by the fetus. Where the maternal values were the lowest, the ratio had a tendency to be smaller, and thus, it would seem that a certain threshold level is necessary in the maternal circulation before this transmission can occur to any significant extent.

The intravenous infusion of ACTH into patients selected for cesarean section raised their 17$\mathrm{OH}-\mathrm{CS}$ levels in a usual manner, but it did not alter the maternal: fetal ratio. This observation can be explained by the fact that either ACTH does not cross the "placental barrier," the fetal levels being merely the reflection of maternal 17-OH-CS concentrations, or that passage across the placenta occurs, but the fetal adrenals do not respond as well as those of the mother. The first hypothesis seems to be more likely in view of the results obtained following compound $\mathrm{F}$ infusion.

It would appear from this study that little or no 17-OH-CS are produced by the fetal adrenal cortex, at least at the end of the third trimester of pregnancy. The levels in cord plasma found in cases of vaginal delivery seem to be conditioned by the high values in the mother; in contrast, following cesarean section, an apparently less stressful situation, the cord values are significantly lower. These observations are consistent with the finding that little or no plasma $17-\mathrm{OH}-\mathrm{CS}$ are detectable in the first few days of life and that normal adult levels are not achieved until after the first week of life (6).

If the fetal adrenal cortex does not produce any corticosteroids, the placenta and/or the maternal adrenals appear to be the most likely sources of $17-\mathrm{OH}-\mathrm{CS}$ in the fetal blood, although there is no evidence against the ovary as a source of the increased steroids. If the placenta synthesizes such hormones, one would have to assume from the data presented that the maternal side of the placenta functions differently from the fetal side. There are no known facts at present to suggest such a differentiation of the placenta but this possibility cannot be disregarded.

The increase in plasma and urinary corticosteroids reported in pregnant Addisonian patients would suggest that the maternal adrenals are not the only site of production of $17-\mathrm{OH}-\mathrm{CS}$ during pregnancy. Progesterone has been isolated from human placenta $(20,21)$ and one might wonder whether this steroid cannot be a precursor of the corticosteroids found in the pregnant Addisonian patients.

In contrast to the 17-OH-CS, the 17-ketosteroid values in cord plasma are higher than the maternal levels $(8,22)$. Both plasma and urinary 17 ketosteroids of the newborn tend to fall gradually during the first few weeks after birth, and do not rise again until the onset of puberty (22). Accordingly, the fetus would appear to be producing primarily 17-ketosteroids and little, if any, 17$\mathrm{OH}-\mathrm{CS}$ at term.

\section{SUMMARY}

In cases of vaginal delivery, labor increased the maternal level of plasma 17-OH-CS over the already elevated value found in the pregnant patient at term. In addition, delivery itself had a tendency to further raise the level.

The surgical trauma associated with cesarean section was probably responsible for the increase observed during that operation; the levels, however, were not as elevated as those noted in the vaginal series.

The concentrations of $17-\mathrm{OH}-\mathrm{CS}$ in cord plasma were approximately one-half to one-fifth of those of the corresponding mother in cases of vaginal delivery, and one-fifth, or a lesser fraction, of 
those of mothers undergoing "elective, repeat cesarean section."

The infusion of $25 \mathrm{mg}$. of ACTH over a period of six hours produced a normal increase of the maternal levels.

The intravenous administration of compound $F$ to mothers just prior to an elective cesarean section demonstrated that, near the end of gestation, this steroid can go through the "placental barrier" but in a definite proportion, the maternal concentration being the determining factor.

From the data presented, it is suggested that, at term, little or no $17-\mathrm{OH}-\mathrm{CS}$ are produced by either the fetal adrenal or the fetal side of the placenta. The most probable sites of biosynthesis of such hormones are the maternal adrenals and/ or the maternal side of the placenta.

\section{ACKNOWLEDGMENTS}

The authors are indebted to Drs. Lawson Wilkins and Nicholson J. Eastman for their great interest in this work.

\section{REFERENCES}

1. Gemzell, C. A., Blood levels of 17-hydroxycorticosteroids in normal pregnancy. J. Clin. Endocrinol. \& Metab., 1953, 13, 898.

2. Bayliss, R. I. S., Browne, J. C. McC., Round, B. P., and Steinbeck, A. W., Plasma 17-hydroxycorticosteroids in pregnancy. Lancet, 1955, 1, 62.

3. Robinson, H. J., Bernhard, W. G., Grubin, H., Wanner, H., Sewekow, G. W., and Silber, R. H., 17,21dihydroxy-20-ketosteroids in plasma during and after pregnancy. J. Clin. Endocrinol. \& Metab., 1955, 15, 317.

4. Assali, N. S., Garst, J. B., and Voskian, J., Blood levels of 17-hydroxycorticosteroids in normal and toxemic pregnancies. J. Lab. \& Clin. Med., 1955, 46, 385.

5. Venning, E., The excretion of various hormone metabolites in normal pregnancy in The Normal and Pathological Physiology of Pregnancy. Baltimore, The Williams \& Wilkins Co., 1943.

6. Klein, R., Fortunato, J., and Papadatos, C., Free blood corticoids in the newborn infant. J. Clin. Invest., 1954, 33, 35.

7. Gemzell, C. A., Variations in plasma levels of 17hydroxycorticosteroids in mother and infant following parturition. Acta endocrinol., 1954, 17, 100.

8. Migeon, C. J., Keller, A. R., and Holmstrom, E., Dehydroepiandrosterone, androsterone and 17-hydroxycorticosteroid levels in maternal and cord plasma in cases of vaginal delivery. Bull. Johns Hopkins Hosp., 1955, 97, 415.

9. Jailer, J. W., In discussion following paper entitled: "Dehydroepiandrosterone and androsterone in ma- ternal and cord plasma" by Migeon, C. J., Report of the Thirteenth M. \& R. Pediatric Research Conference on Adrenal Function in Infants and Children, Syracuse, Nov. 3-4, 1954, p. 26.

10. Hills, A. G., Venning, E. H., Dohan, F. C., Webster, G. D., Jr., and Richardson, E. M., Pregnancy and adrenocortical function: endocrine studies of pregnancy occurring in two adrenal-deficient women. J. Clin. Invest., 1954, 33, 1466.

11. Nelson, D. H., and Samuels, L. T., A method for the determination of 17-hydroxycorticosteroids in blood: 17-hydroxycorticosterone in the peripheral circulation. J. Clin. Endocrinol. \& Metab., 1952, 12, 519.

12. Bush, I. E., Methods of paper chromatography of steroids applicable to the study of steroids in mammalian blood and tissues. Biochem. J., 1952, 50, 370.

13. Migeon, C. J., Sandberg, A. A., Bliss, E. L., and Keller, A. R., Non-conjugated adrenocortical steroids in human plasma. Comparison of the Nelson and Samuels method with paper chromatographic techniques. J. Clin. Endocrinol. \& Metab., 1956, 16, 253.

14. Eik-Nes, K., Sandberg, A. A., Nelson, D. H., Tyler, F. H., and Samuels, L. T., Changes in plasma levels of 17-hydroxycorticosteroids during the intravenous administration of ACTH. I. A test of adrenocortical capacity in the human. J. Clin. Invest., 1954, 33, 1502.

15. Christy, N. P., Wallace, E. Z., and Jailer, J. W., The effect of intravenously-administered ACTH on plasma 17,21-dihydroxy-20-ketosteroids in normal individuals and in patients with disorders of the adrenal cortex. J. Clin. Invest., 1955, 34, 899.

16. Bush, I. E., and Sandberg, A. A., Adrenocortical hormones in human plasma. J. Biol. Chem., 1953, 205, 783 .

17. Sandberg, A. A., Eik-Nes, K., Migeon, C. J., and Samuels, L. T., Metabolism of adrenal steroids in dying patients. In preparation.

18. Sandberg, A. A., Eik-Nes, K., Samuels, L. T., and Tyler, F. H., The effect of surgery on the blood levels and metabolism of 17-hydroxycorticosteroids in man. J. Clin. Invest., 1954, 33, 1509.

19. Tyler, F. H., Schmidt, C. D., Eik-Nes, K., Brown, H., and Samuels, L. T., The role of the liver and the adrenal in producing elevated plasma 17hydroxycorticosteroid levels in surgery. J. Clin. Invest., 1954, 33, 1517.

20. Pearlman, W. H., and Cerceo, E., The isolation of progesterone from human placenta. J. Biol. Chem., 1952, 198, 79.

21. Salhanick, H. A., Noall, M. W., Zarrow, M. X., and Samuels, L. T., The isolation of progesterone from human placentae. Science, 1952, 115, 708.

22. Gardner, L. I., and Walton, R. L., Plasma 17ketosteroids of the human fetus: demonstration of concentration gradient between cord and maternal circulations. Helvet. paediat. acta, 1954, 9, 311. 